\title{
PENELITIAN
}

\section{GAMBARAN KLIEN PERILAKU KEKERASAN DI RUMAH SAKIT JIWA PUSAT BOGOR DAN RUMAH SAKIT JIWA PUSAT JAKARTA: SUATU SURVEI}

\author{
Budi Anna Keliat , Mustikasari, Ria Utami Panjaitan *
}

\begin{abstract}
Abstrak
Penelitian ini bertujuan untuk memperoleh gambaran tentang klien dengan perilaku kekerasan yaitu jenis kelamin, lama rawat klien, diagnosis medik, terapi medik dan status pulang klien di RSJP Bogor dan RSJP Jakarta. Responden terdiri dari 68 klien, 48 klien rawat di RSJP Bogor dan 20 klien rawat di RSJP Jakarta. Hasil penelitian didapatkan bahwa lama rawat klien di RSJP Bogor dan RSJP Jakarta mendekati sama, yaitu 33 orang (48,53\%) sama dan kurang dari 10 hari, dan 35 orang (51,47\%) lebih dari 10 hari. Paling banyak diagnosa medis adalah schizophrenia (63,23\%) dan terapi medis adalah chlorpromazine (CPZ), halloperidol (HLP) and trihexyphenidile (THP). Hasil penelitian memperlihatkan bahwa 33 klien (48,33\%) dirawat selama kurang lebih 10 hari, 35 klien lainnya $(54,47 \%)$ dirawat lebih dari 10 hari. Lebih dari $70 \%$ status pulang klien pulang dari rumah sakit adalah atas ijin rumah sakit.
\end{abstract}

Kata kunci: perilaku kekerasan, lama rawat, diagnosa medis, terapi medis, status pulang

\begin{abstract}
This study was almed at describing the characteristic of client with violence behavior who hospitalized in the Bogor mental hospital and in the Jakarta mental hospital. The characteristics were involved sex, length of stay, medical diagnoses and therapies and the condition of the respon dents at the time of discharge. The respondent were 48 clients who were hospitalized in the Bogor mental hospital and 20 clients who were hospitalized in the Jakarta metal hospital. The result of this study revealed that the length of stay of the client at both the Bogor mental hospital and the Jakata mental hospital was guite equel. Thirtytree clients (48,33\%) were hospitalized for less or equel than 10 days and thirtyfive clients (35,47\%) were hospitalized for more than 10 days. Most of the clients $(62,23 \%)$ were diagnosed as schizophrenia and chlorpromazine (CPZ), halloperidol (HLP) and trihexyphenidile (THP) were the most frequent drug used by the client during hospitalization. More than $70 \%$ of clients were discrarged from the hospital in good condition withthe permission from the hospial.
\end{abstract}

Key words: violence, length of stay, medical diagnosis, medical therapy, discharge condition.

\section{LATAR BELAKANG}

Kesehatan jiwa merupakan masalah kesehatan yang dapat mengganggu kesehatan secara keseluruhan. Berdasarkan hasil penelitian yang dilakukan pada tahun 1990 tentang Disability Adjusted Life Year (DALY) bahwa masalah kesehatan jiwa menempati urutan ketiga dari tujuh masalah kesehatan terbesar di dunia (WHO, 1999). Salah satu bentuk dari masalah kesehatan jiwa adalah perilaku kekerasan. Perilaku kekerasan yang terjadi segera dilakukan penanganan secara benar, agar tidak menambah parah kondisi klien dan beban keluarga menjadi berkurang.
Perilaku kekerasan merupakan cara individu menyelesaikan masalahnya, yang dapat dimanifestasikan secara fisik (mencederai diri, peningkatan mobilitas tubuh), psikologis (emosional, marah, mudah tersinggung, menentang), sosial (mencederai lingkungan dan orang lain, menghujat, bermusuhan), spiritual (merasa dirinya sangat berkuasa, tidak bermoral) (Stuart \& Laraia, 1998). Bentuk perilaku di atas dapat terjadi pada setiap individu, dan jika berlanjut dapat terjadi masalah gangguan jiwa. Perilaku kekerasan merupakan perilaku yang banyak digunakan oleh klien gangguan jiwa yang dirawat di rumah sakit jiwa. 
Berdasarkan kondisi tersebut maka penelitian ini akan memberikan gambaran yang lebih jelas tentang klien perilaku kekerasan. Selain itu dapat juga digunakan bagi penelitian berkelanjutan dan pengembangan ilmu pengetahuan khususnya keperawatan jiwa.

Tujuan umum yang ingin dicapai dari penelitian ini adalah diperolehnya gambaran klien yang dirawat karena perilaku kekerasan di Rumah Sakit Jiwa Pusat (RSJP) Bogor dan Rumah Sakit Jiwa Pusat Jakarta. Sedangkan tujuan khusus yang ingin dicapai adalah teridentifikasinya 1) jenis kelamin, 2) lama rawat, 3) karakteristik diagnosis medik, 4) terapi medik dan 5) status pulang klien perilaku kekerasan di RSJP Bogor dan RSJP Jakarta bulan Maret sampai dengan Agustus 1999.

Informasi yang didapatkan dari penelitian ini akan menjadi masukan bagi pelayanan keperawatan dalam mengembangkan asuhan keperawatan perilaku kekerasan. Data yang didapatkan akan berguna untuk peningkatan penelitian perilaku kekerasan berkelanjutan dan pengembangan ilmu pengetahuan khususnya keperawatan jiwa (perilaku kekerasan).

\section{BAHAN DAN CARA KERJA}

Penelitian ini merupakan penelitian deskriptif yaitu berupa survei dengan rancangan cross sectional. Dengan variabel yang diteliti adalah lama rawat, karakteristik diagnosis medik, terapi medik dan status pulang klien perilaku kekerasan di Rumah Sakit Jiwa Pusat Bogor dan Rumah Sakit Jiwa Pusat Jakarta. Secara lengkap kerangka konsep dapat dilihat pada skema 1.

Skema 1

Kerangka konsep
Penelitian dilakukan di Rumah Sakit Jiwa Pusat Bogor dan Rumah Sakit Jiwa Pusat Jakarta yang merupakan tempat lahan praktek mahasiswa Fakultas Ilmu Keperawatan Universitas Indonesia khususnya untuk mata ajaran Keperawatan Jiwa. Sampel yang diambil adalah 68 status medik klien pada bulan Maret sampai dengan Agustus 1999 dengan rincian 48 klien di Rumah Sakit Jiwa Pusat Bogor dan 20 klien klien di Rumah Sakit Jiwa Pusat Jakarta.

Pengumpulan data dilakukan dengan menggunakan instrumen daftar pertanyaan dan chek list tentang jenis kelamin, diagnosis medik, terapi medik, status keperawatan saat pulang, tanggal dirawat, dan tanggal pulang. Kegiatan ini dilakukan oleh tim peneliti, yaitu 1 orang di RSJP Bogor dan 1 orang di RSJP Jakarta. Instrumen diisi peneliti mulai bulan Maret sampai dengan bulan Agustus 1999 dengan melihat rekam medik klien yang pulang.

Pengolahan data dilakukan secara manual dengan memilah, membuat kolom, memasukkan kedalam kolom, dan membuat rekapitulasi hasil dari masing-masing pertanyaan. Hasil yang diperoleh ditampilkan dalam bentuk tabel distribusi frekuensi.

\section{HASIL}

\section{Jenis Kelamin}

Jenis kelamin klien perilaku kekerasan yang pulang pada bulan Maret sampai dengan bulan Agustus 1999 di RSJP Bogor adalah 16 orang perempuan dan 32 orang laki-laki. Sedangkan di RSJP Jakarta adalah 7 orang perempuan dan 13 orang laki-laki (tabel 1).

\begin{tabular}{|l|l|l|}
\hline \multicolumn{1}{|c|}{$\begin{array}{l}\text { KARAKTERISTIK } \\
\text { KLIEN }\end{array}$} & $\begin{array}{l}\text { Klien Perilaku Kekerasan } \\
\text { Rumah Sakit Jiwa Pusat Bogor } \\
\text { - Lama rawat } \\
\text { - Diagnosis medik } \\
\text { - Terapi medik } \\
\text { - Status pulang klien }\end{array}$ & $\begin{array}{l}\text { Jakarta bulan Maret s/d Agustus } \\
1999\end{array}$ \\
\cline { 1 - 1 } & &
\end{tabular}


Tabel 1

Distribusi Klien Perilaku Kekerasan Berdasarkan Jenis Kelamin

Periode Maret - Agustus 1999

\begin{tabular}{|c|c|c|c|c|}
\hline Jenis kelamin & RSJP & Bogor & RSJP & Jakarta \\
\hline & Jumlah & Persen & Jumlah & Persen \\
\hline Perempuan & 16 & 33,33 & 7 & 35,00 \\
\hline Laki-laki & 32 & 66,67 & 13 & 65,00 \\
\hline Total & 48 & 100 & 20 & 100 \\
\hline
\end{tabular}

Berdasarkan data di atas bahwa jumlah klien lakilaki baik di RSJP Bogor maupun di RSJP Jakarta 2 kali lebih banyak dibandingkan jumlah klien perempuan. Hal ini menunjukkan bahwa RSJP Bogor dan RSJP Jakarta memiliki karakteristik yang hampir sama dimana pada bulan Maret sampai dengan Agustus 1999 klien terbanyak adalah laki-laki.

\section{Lama Rawat}

Lama rawat klien di RSJP Bogor dan RSJP Jakarta dikategorikan menjadi 2 yaitu < 10 hari dan $>10$ hari (tabel2).

Tabel 2

Perbandingan Lama Rawat Klien Perilaku Kekerasan RSJP Bogor dengan RSJP Jakarta Periode Maret - Agustus 1999

\begin{tabular}{|c|c|c|c|c|c|c|c|c|c|c|}
\hline \multirow{3}{*}{$\begin{array}{l}\text { Lama } \\
\text { Rawat }\end{array}$} & \multicolumn{4}{|c|}{ RSJP Bogor } & \multicolumn{4}{|c|}{ RSJP Jakarta } & \multirow{2}{*}{\multicolumn{2}{|c|}{ Total }} \\
\hline & \multicolumn{2}{|c|}{ Perempuan } & \multicolumn{2}{|c|}{ Laki-laki } & \multicolumn{2}{|c|}{ Perempuan } & \multicolumn{2}{|c|}{ Laki-laki } & & \\
\hline & Jumlah & Persen & Jumlah & Persen & Jumlah & Persen & Jumlah & Persen & Jumlah & Persen \\
\hline $\begin{array}{l}\leqslant \quad 10 \\
\text { hari }\end{array}$ & 3 & 18.75 & 18 & 56.25 & 5 & 71.43 & 7 & 53.85 & 33 & 48,53 \\
\hline $\begin{array}{l}>10 \\
\text { hari }\end{array}$ & 13 & 81.25 & 14 & 43.75 & 2 & 28.57 & 6 & 46.15 & 35 & 51,47 \\
\hline
\end{tabular}

Berdasarkan data tentang lama rawat di atas tampak bahwa antara lama rawat klien perempuan dan laki-laki di RSJP Bogor dan RSJP Jakarta berbeda. Lama rawat di RSJP Bogor untuk perempuan lebih lama (> 10 hari), sedangkan laki-laki lebih pendek lama rawatnya ( $\leq 10$ hari). DiRSJP Jakarta klien perempuan dan laki-laki sama-sama lebih banyak yang lama rawatnya sama dan kurang dari 10 hari.

\section{Terapi Medik}

Terapi medik yang banyak digunakan dan dipakai untuk klien dengan perilaku kekerasan di RSJP Bogor dan RSJP Jakarta adalah sama yaitu Clorpromazin (CPZ), Haloperidol (HLP) dan Trihexyphenidile (THP).

Tabel 3

Terapi Medik Klien Perilaku Kekerasan RSJP Bogor dan RSJP Jakarta

Periode Maret - Agustus 1999

\begin{tabular}{|c|c|c|c|c|c|c|c|c|}
\hline \multirow{3}{*}{$\begin{array}{l}\text { Terapi } \\
\text { Medik }\end{array}$} & \multicolumn{4}{|c|}{ RSJP Bogor } & \multicolumn{4}{|c|}{ RSJP Jak arta } \\
\hline & \multicolumn{2}{|c|}{ Perempuan } & \multicolumn{2}{|c|}{ Laki-laki } & \multicolumn{2}{|c|}{ Perempuan } & \multicolumn{2}{|c|}{ Laki-laki } \\
\hline & Jumlah & Persen & Jumlah & Persen & Jumlah & Persen & Jumlah & Persen \\
\hline $\begin{array}{l}\text { CPZ, HLP, } \\
\text { THP }\end{array}$ & 16 & 100 & 32 & 100 & 6 & 100 & 13 & 100 \\
\hline
\end{tabular}




\section{Diagnosis Medik}

Berdasarkan penelitian bahwa diagnosis medik klien perilaku kekerasan yang paling banyak adalah skizofrenia paranoid (40,63\%) di RSJP Bogor dan skizofrenia hebefrenik $(66,67 \%)$ di RSJP Jakarta (tabel 4).

Tabel 4

Distribusi Diagnosa Medik Klien Perilaku Kekerasan di RSJP Bogor dengan RSJP Jakarta

Periode Maret - Agustus 1999

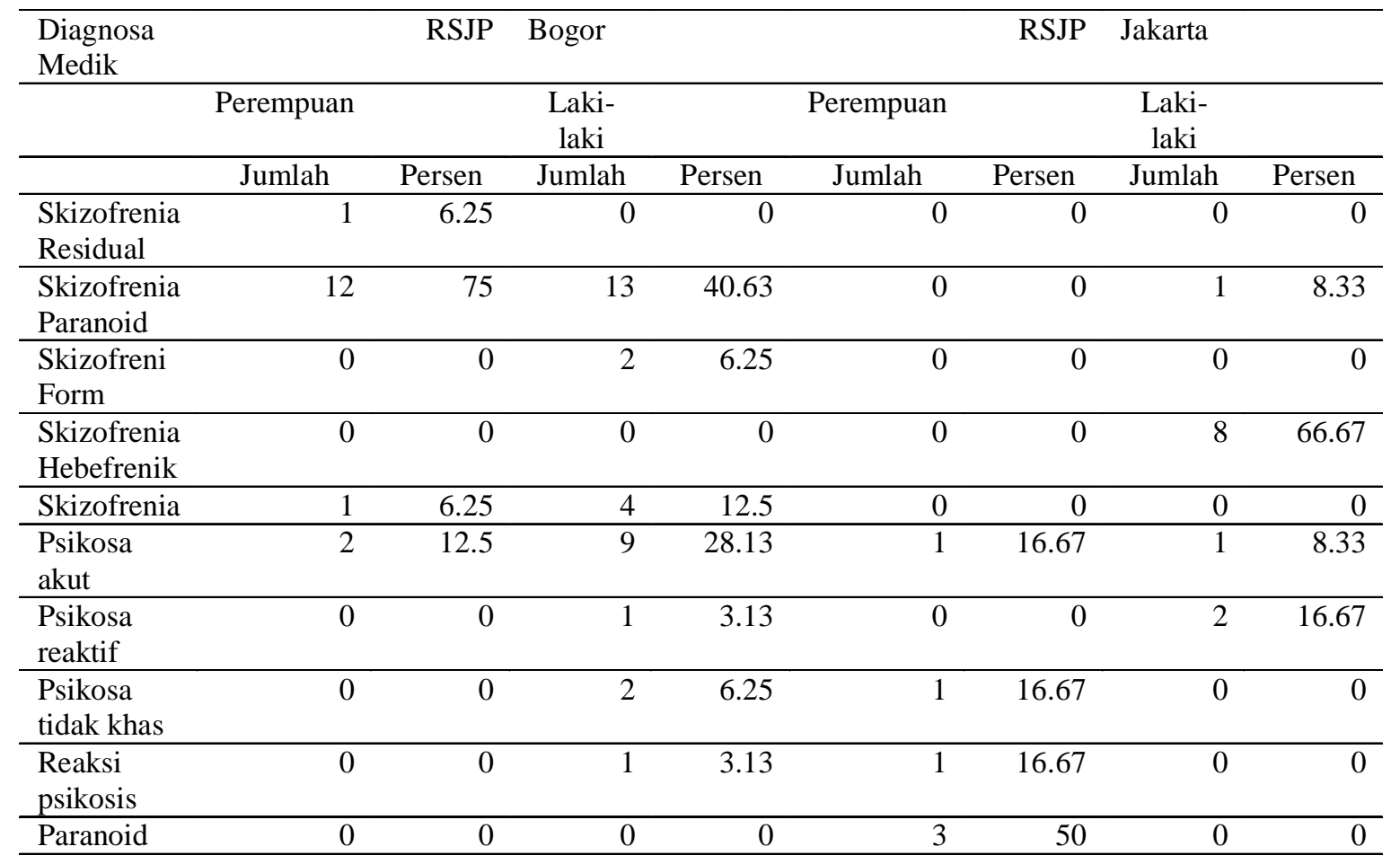

\section{Status Pulang}

Berdasarkan hasil penelitian didapatkan terbanyak adalah sama yaitu pulang tuntas baik bahwa status pulang klien perilaku kekerasan di RSJP Bogor maupun RSJP Jakarta

Tabel 5

Perbandingan status pulang klien perilaku kekerasan RSJP Bogor dengan RSJP Jakarta Periode Maret - Agustus 1999.

\begin{tabular}{|c|c|c|c|c|c|c|c|c|}
\hline \multirow{3}{*}{$\begin{array}{l}\text { Status } \\
\text { pulang }\end{array}$} & \multicolumn{2}{|c|}{ RSJP } & \multicolumn{2}{|c|}{ 3ogor } & \multicolumn{2}{|c|}{ RSJP } & \multicolumn{2}{|l|}{ akarta } \\
\hline & $\begin{array}{c}\text { Perem } \\
\text { puan }\end{array}$ & & aki-laki & & $\begin{array}{c}\text { Perem } \\
\text { puan }\end{array}$ & & Laki-laki & \\
\hline & Jumlah & Persen & Jumlah & Persen & Jumlah & Persen & Jumlah & Persen \\
\hline Tuntas & 14 & 81.50 & 25 & 78.13 & 4 & 57.14 & 9 & 69.23 \\
\hline Paksa & 1 & 6.25 & 2 & 6.25 & 3 & 42.86 & 0 & 0 \\
\hline Kabur & 1 & 6.25 & $\overline{5}$ & 15.63 & $\overline{0}$ & 0 & 4 & 30.77 \\
\hline
\end{tabular}




\section{PEMBAHASAN}

\section{Jenis Kelamin}

Pada kedua rumah sakit (RSJP Bogor dan RSJP Jakarta) dari hasil survei didapatkan bahwa laki-laki lebih banyak melakukan perilaku kekerasan dibandingkan dengan perempuan. Hal ini disebabkan karena laki-laki menggunakan mekanisme ego berupa rasionalisasi, yaitu mengemukakan penjelasan yang tampak logis dan dapat diterima masyarakat untuk menghalalkan/membenarkan impuls, perasaan, perilaku, dan motif yang tidak dapat diterima. Sedangkan pada perempuan, mekanisme ego yang digunakan adalah supresi, yaitu pengesampingan secara disadari tentang pikiran, impuls atau ingatan yang menyakitkan atau bertentangan, dari kesadaran seseorang (Herawati, 1997).

\section{Lama Rawat}

Klien yang dirawat di rumah sakit jiwa mempunyai rata-rata lama hari rawat yang tinggi yaitu 54 hari (DepKes, 2000) dan klien yang paling lama dirawat adalah skizofrenia yaitu 64,8 hari (DepKes, 1996).

Penelitian yang dilakukan Morrisor $\leq 1994$ ) didapatkan bahwa rata-rata lama hari rawat klien perilaku kekerasan dengan diagnosis skizofrenia adalah 14 hari. Sedangkan dari hasil penelitian didapatkan lama rawat klien laki-laki di RSJP Bogor dan RSJP Jakarta didapatkan 10 hari. Untuk perempuan lama rawat di RSJP Bogor lebih lama dibandingkan dengan RSJP Jakarta.

Menurut Boyd dan Nikart (1998) pembagian lama rawat klien dengan perilaku kekerasan dibagi menjadi 4 (empat) yaitu brief short term ( $<7$ hari), very short term (7-14 hari), traditional short term (15-21 hari) dan long term care (> 21-120 hari). Sesuai dengan pembagian lama rawat klien perilaku kekerasan maka lama rawat klien dengan perilaku kekerasan di RSJP Bogor dan RSJP Jakarta termasuk dalam kategori very short term (7-14 hari). Singkatnya hari rawat klien di RSJP Bogor dan RSJP Jakarta dapat disebabkan oleh self care, self control dan percaya diri yang dimiliki klien dan keluarga (Swanson dan Nies, 1997) yang merupakan hasil dari pemberdayaan klien.

\section{Terapi Medik}

Stuart dan Laraia (1998) mengemukakan manajemen perilaku kekerasan pada klien gangguan jiwa terdiri dari 3 (tiga) strategi. Salah satu strategi yang ke dua adalah strategi antisipasi termasuk pemberian obat anti psikotik.

Untuk klien dengan perilaku kekerasan, baik di RSJP Bogor dan RSJP Jakarta, terapi medik yang diberikan adalah sama yaitu antipsikotik. Klien dengan perilaku kekerasan akan mendapatkan CPZ dan HLP yang digunakan untuk menanggulangi masalah psikotik (manifestasi psikotik). Biasanya obat tersebut menimbulkan efek samping yaitu gangguan parkinson. Untuk menanggulanginya klien diberikan obat antiparkinson yaitu THP.

Hasil penelitian sesuai dengan teori, yaitu obat antipsikotik mempunyai efek untuk mengendalikan gejala positif yaitu perilaku kekerasan (Kaplan, et al, 1996).

\section{Diagnosis Medik}

Menurut informasi rumah sakit (Depkes, 1996) diagnosa klien yang keluar dari rumah sakit jiwa pada tahun 1994 adalah skizofrenia $(53,7 \%)$. Hasil survei ini sesuai dengan kondisi secara umum di Indonesia. Penelitian yang dilakukan oleh Florez (2001) menemukan $72 \%$ responden mengatakan klien skizofrenia tidak dapat bekerja teratur, $47 \%$ responden mengatakan kepribadian terganggu dan $14 \%$ responden mengatakan klien berbahaya. Hasil penelitian menunjukkan bahwa klien gangguan jiwa dengan perilaku kekerasan terbanyak adalah skizofrenia yaitu skizofrenia paranoid di RSJP Bogor dan skizofrenia hebefrenik di RSJP Jakarta.

Diagnosis skizofrenia paranoid lebih baik dari skizofrenia lain secara klinis baik dalam sympom free selama klien patuh makan obat (Wibisono, 2003). Hal ini juga didukung bahwa kecerdasan klien dengan diagnosis skizofrenia paranoid tidak terganggu (Kaplan, et al, 1996). 


\section{Status Pulang}

Klien yang mengalami masalah perilaku kekerasan diharapkan pulang ke rumah atas ijin rumah sakit. Oleh karena itu perawat mempunyai peran dalam meningkatkan kemampuan klien menyalurkan marah secara konstruktif. Namun perlu diteliti atau dikaji lebih lanjut sejauh mana peran serta atau konstribusi perawat dalam menentukan ijin pulang klien.

Berdasarkan pengalaman atau kenyataan di rumah sakit, status pulang klien dari rumah sakit ada 3 (tiga) macam, yaitu: atas ijin rumah sakit, atas permintaan keluarga, atas kehendak klien (tanpa sepengetahuan rumah sakit dan keluarga) (RSJP Bogor, 1996). Dari hasil penelitian didapatkan bahwa status pulang klien terbanyak adalah pulang tuntas baik di RSJP Bogor dan RSJP Jakarta.

Pulang tuntas yang dimaksudkan adalah kemampuan baru klien dalam menyelesaikan masalahnya. Kemampuan baru adalah mekanisme koping berupa perilaku yang dipelajari dan dilatih lalu digunakan untuk menyelesaikan masalah yang dihadapi Stuart dan Laraia, 1998).

Klien mempunyai kapasitas untuk mengembangkan self care agency agar dapat melakukan self care (Orem, 2001). Koping baru yang dikembangkan adalah pencegahan perilaku kekerasan untuk menggantikan koping mal adaptif yaitu perilaku kekerasan.

\section{KESIMPULAN}

Gambaran klien perilaku kekerasan merupakan faktor yang penting dalam menunjang pengembangan penelitian berkelanjutan dan pengembangan ilmu pengetahuan khususnya keperawatan jiwa (perilaku kekerasan). Dari 68 responden yang terdiri dari 48 klien RSJP Bogor dan 20 klien RSJP Jakarta, periode Maret - Agustus 1999, menunjukkan bahwa lama hari rawat klien di RSJP Bogor dan RSJP Jakarta hampir sama, yaitu 33 orang $(48,53 \%)$ kurang dari dan sama dengan 10 hari, dan 35 orang $(51,47 \%)$ lebih dari 10 hari. Diagnosis medik yang paling banyak adalah skizofrenia $(63,23 \%)$, dan terapi medik yang digunakan adalah chlorpromazine (CPZ), halloperidol (HLP) and trihexyphenidile (THP). Kondisi klien saat pulang adalah $76,4 \%$ berstatus pulang atas ijin rumah sakit (MS \& Kun).

* Budi Anna Keliat, Mustikasari, Ria Utami Panjaitan: Staf pengajar Keperawatan Jiwa \& Komunitas Fakultas Ilmu Keperawatan Universitas Indonesia

\section{KEPUSTAKAAN}

Boyd, M.A., and Nikart, M.A. (1998). Psychiatric nursing contemporary practice. Philadelphia: Lippincott.

Depkes RI., Dirjen Yan.Med. (1996). Informasi rumah sakit: Seri 3 morbiditas dan mortalitas 1995. Jakarta: Dep.Kes. RI.

(2000). Kebijakan pengembangan tenaga kesehatan tahun 2000-2010. Jakarta: DepKes RI.

Florez, J.A. (2001). Ministerial round tables: mental health. WHO: Fifty-fourth World Health Assembly.

Herawati, N. (1997). Asuhan keperawatan klien dengan ansietas. (kumpulan makalah).

Kaplan, H.I., Sadock, B.J., and Grebb, J.A. (1996). Synopsis of psychiatry: Behavioral sciences clinical psychiatry. (7h ed). Baltimore: Williams dan Wilkins.

Orem, D.E. (2001). Nursing cencepts of practice. $\left(6^{\text {th }} \mathrm{ed}\right)$. St. Louis: Mosby

RS Jiwa Pusat Bogor. (1996). Prosedur pasien pulang, prosedur pasien pulang atas permintaan keluarga (pulang paksa), prosedur penanganan pasien melarikan diri (meninggalkan rumah sakit tanpa izin). Bogor: Standar pelayanan keperawatan dan standar pelayanan medik.

Stuart, G. W. and Laraia, M.T. (1998). Principles practice psychiatric nursing (6 $\left.6^{\text {th }} e d\right)$. ST. Louis Mosby.

Swanson, J.M., and Nies, M.A. (1997). Community health nursing: promoting the health of aggregates. Philadelphia: W. B. Saunders Company.

Wibisono, S. (2003). Hasil wawancara tentang skizofrenia. Jakarta: tidak dipublikasikan. 